\title{
FLUORINE-FREE MOULD SLAGS FOR SLAB CASTING: UTILISATION OF THE HOT THERMOCOUPLE TECHNIQUE TO BUILD TTT DIAGRAMS
}

\author{
Jeferson Leandro Klug ' \\ René Hagemann ${ }^{2}$ \\ Nestor Cezar Heck ${ }^{3}$ \\ Antônio Cezar Faria Vilela ${ }^{4}$ \\ Piotr Roman Scheller ${ }^{5}$
}

\begin{abstract}
The elimination of fluorine from slags is necessary because F-bearing materials pollute the environment and cause machinery corrosion at steelworks. Regarding the development of F-free mould slags for slab casting, the main problem is how to control the heat transfer between steel shell and mould. In commercial products the heat transfer control is obtained through the crystallisation of cuspidine $\left(3 \mathrm{CaO} \cdot 2 \mathrm{SiO}_{2} \cdot \mathrm{CaF}_{2}\right)$ from mould slag. Thus, the fluorine-free slag which would be used as the substitute must show similar crystallisation behaviour. This paper shows results of a cooperation work between Technische Universität Bergakademie Freiberg and Universidade Federal do Rio Grande do Sul. Ti-bearing slags were studied through the Single Hot Thermocouple Technique, building time-temperature-transformation (TTT) diagrams. The results indicate that the system $\mathrm{CaO}-\mathrm{SiO}_{2}-\mathrm{TiO}_{2}-\mathrm{Na}_{2} \mathrm{O}$ can be used as substitute for F-bearing slags, regarding crystallisation behaviour, since the incubation times at TTT diagram can be similar to commercial products. This is possible because addition of $\mathrm{Na}_{2} \mathrm{O}$ shorten intensely the incubation times from the $\mathrm{CaO}-\mathrm{SiO}_{2}-\mathrm{TiO}_{2}$ slag system.
\end{abstract}

Key words: Mould slags; Slab casting; Hot thermocouple technique; TTT diagrams.

\section{INTRODUCTION}

Mould powders or mould fluxes are synthetic slags which should fulfil different functions during continuous casting of steel,(I) as (i) protect the steel meniscus from oxidation, (ii) absorb inclusions floating up from the steel, (iii) provide thermal insulation to prevent the steel from freezing, (iv) provide the optimum level of horizontal heat transfer between shell and mould and ( $v$ ) provide lubrication of the steel shell. The mould slag i.e. the mould powder which was melted in the mould during continuous casting is one of the most important slags in the melting shop.

The choice of the mould powder for slab casting is a difficult task because of the complicated nature of the powder composition, and because the mould powder has many important functions. Due to the complex requi- rements in the industrial process the choice is based on recommendations from manufacturers and trials in the caster, followed by investigations on the quality of the slabs. Normally in the melting shop different compositions - with reasonably small differences - are tested to get good results. ${ }^{(1,2)}$

The presence of crystals has a decisive effect on both the lubrication and the heat transfer between the mould and the steel strand. The crystallisation behaviour of the mould slag depends on the thermal conditions between mould wall and strand and the slag composition. ${ }^{(3)}$ When a layer is formed directly on the mould surface either at the beginning of the casting or later, it will form at first in a glassy state. If there is sufficient driving potential i.e. if there is enough time and the temperature is sufficiently high, devitrification of the layer will take place, resulting in a crystalline phase. ${ }^{(2)}$ The presence of crystals

\footnotetext{
'PhD student at Federal University of Rio Grande do Sul - UFRGS, Brazil, Institute or Iron and Steel Technology, Freiberg University of Mining and Technology, Leipziger Straße 34, 09599 Freiberg, Germany. E-mail: klug@ufrgs.br

${ }^{2} \mathrm{PhD}$ student, Institute or Iron and Steel Technology, Freiberg University of Mining and Technology, Leipziger Straße 34, 09599, Freiberg, Germany.

E-mail: rene.hagemann@iest.tu-freiberg.de

${ }^{3}$ Prof. Dr.-Ing., Program of Postgraduate Studies in Mining, Metals and Materials Engineering, School of Engineering, Federal University of Rio Grande do Sul - UFRGS, Av. Bento Gonçalves, 9500, Setor 4, Prédio 74, Sala 21 I, Campus do Vale, Cep 9150I-970, Porto Alegre, RS, Brazil.

E-mail: heck@ufrgs.br

${ }^{4}$ Prof. Dr.-Ing., Program of Postgraduate Studies in Mining, Metals and Materials Engineering, School of Engineering, Federal University of Rio Grande do Sul - UFRGS, Av. Bento Gonçalves, 9500, Setor 4, Prédio 74, Sala 21 I, Campus do Vale, Cep 9150I-970, Porto Alegre, RS, Brazil.

E-mail: vilela@ufrgs.br

${ }^{5}$ Prof. Dr.-Ing. habil., Head of the Institute or Iron and Steel Technology, Freiberg University of Mining and Technology, Leipziger Straße 34, 09599,

Freiberg, Germany. E-mail: scheller@iest.tu-freiberg.de
} 
in the liquid layer increases the friction between mould and strand, leading to high incidence of sticker breakouts. Mould slags with a high crystallisation tendency are deleterious to high-speed casting conditions. On the other hand, a high crystallisation tendency is beneficial in the casting of peritectic steel grades. Anyway, it is clear that in the continuous casting mould slags crystallisation control is a matter of utmost importance.

Commercial mould powders contain fluorine, usually as calcium fluoride $\left(\mathrm{CaF}_{2}\right)$. There is a clear trend in industry to eliminate fluorine from slags which are used during production of steel. Regarding continuous casting process fluorine in mould powders is undesirable from the environmental and health points of view due to the following reasons: (i) evolves easily from slags, producing health-injurious gaseous substances, such as hydrofluoric acid; (ii) creates problems for storage and utilisation of solid waste and (iii) causes machinery corrosion. Regarding machinery corrosion the hydrofluoric acid, which is generated during continuous casting process from mould powder, increases dramatically the corrosion rate especially below the mould where there is a high amount of water accelerating the corrosion process. ${ }^{(4)}$

The main problem related to the development of fluorine-free mould powders for slab casting is how to control the heat transfer between steel shell and mould. The crystallisation of cuspidine $\left(3 \mathrm{CaO} .2 \mathrm{SiO}_{2} \cdot \mathrm{CaF}_{2}\right)$ from mould flux is thought to be the most effective way for the heat transfer control. Although the mechanism of the heat transfer control by the crystallisation of cuspidine has not been determined yet, two ideas have been proposed. One is that radiation heat flux is decreased by scattering at the boundary between the crystalline and the liquid layers and the other is that total heat flux is decreased by the large thermal resistance of the air gap formed as a result of the solidification shrinkage. Anyway, the crystallisation of cuspidine from mould flux has the great effect on heat transfer control. ${ }^{(5)}$

There are some papers indicating that $\mathrm{TiO}_{2}$-bearing raw materials can be used to replace fluorine-bearing raw materials, regarding the heat transfer control function, by formation of $\mathrm{TiO}_{2}$ crystals instead of cuspidine. ${ }^{(5-7)}$

Nakada and Nagata ${ }^{(5)}$ analysed the basic system $\mathrm{CaO}-\mathrm{SiO}_{2}-\mathrm{TiO}_{2}$ evaluating the possibility of having it as a candidate for fluorine-free mould flux through the crystallisation of $\mathrm{CaO} \cdot \mathrm{SiO}_{2} \cdot \mathrm{TiO}_{2}$, determining the time-temperature-transformation (TTT) diagram of two slag compositions through differential thermal analysis (DTA). They concluded that it is possible to get the heat transfer control function, but the thickness of the crystalline layer was found to be smaller than that of the crystalline layer resulting from cuspidine precipitation. Then, they suggested that it is worth investigating the effect of $\mathrm{Na}_{2} \mathrm{O}$ addition in the $\mathrm{CaO}-\mathrm{SiO}_{2}-\mathrm{TiO}_{2}$ slags, since in this way it would be possible to decrease the incubation times and consequently to increase the thickness of the crystalline layer.

Wen et al.(6) evaluated titanium-bearing blast furnace slags as a base material to develop F-free mould powders, evaluating their properties and their performance through laboratory experiments and plant trials. According to them the industrial trials indicated that F-free mould powders can effectively control mould heat transfer through perovskite $\left(\mathrm{CaO} . \mathrm{TiO}_{2}\right)$ precipitated in the infiltrated slag layer instead of cuspidine in fluorine-bearing powder, with better slab surface quality than fluoride-bearing powders in terms of crack index.

Xin Qi, Wen and Ping Tang ${ }^{(7)}$ studied mould slags using a device which simulates the heat flux through the mould slag film, based on the copper finger method, and reported that when increasing $\mathrm{TiO}_{2}$ content in fluorine-free mould powders the activation energy for crystallisation from glassy solid mould fluxes and the activation energy for crystallisation from liquid mould fluxes are reduced. Thus, according to their report, from the perspective of the activation energy for crystallisation the fluorine-free titanium-bearing mould slags have already reached the level of fluorine-bearing industrial mould slags, and can be used to replace them.

The crystallisation rate of crystals in fluorine-free titanium-bearing mould slags must be similar to the crystallisation rate of cuspidine in commercial mould fluxes. It is assumed that the crystallisation rate of crystals is linked with incubation times in time-temperature-transformation diagrams (TTT diagrams).

The Single Hot Thermocouple Technique (SHTT) can be used to build TTT diagrams. With this technique the sample is put on one thermocouple tip, heated and cooled at the desired rates. The advantage is to allow in situ observation of melting and solidification under various thermal conditions. Due to the low mass of the system (sample and thermocouple) high heating and cooling rates can be easily obtained $\left(>3000^{\circ} \mathrm{C} / \mathrm{min}\right)$. Besides SHTT, using the hot thermocouple technique another experimental mode is also possible: the Double Hot Thermocouple Technique (DHTT). With the DHTT the solidification behaviour can be observed in situ applying temperature gradients, simulating the conditions during continuous casting. In this mode the slag sample is placed between the tips of two thermocouples. Both sides can be controlled independently and mould-like temperature gradients or heat peaks can be applied. ${ }^{(8)}$

\section{I Objective}

The objective is to evaluate the possibility of reproducing the crystallisation behaviour of cuspidine during continuous casting, building TTT diagrams through the 
Single Hot Thermocouple Technique in the $\mathrm{CaO}-\mathrm{SiO}_{2}-$ $\mathrm{TiO}_{2}-\mathrm{Na}_{2} \mathrm{O}$ slag system.

\section{MATERIALS AND METHODS}

\section{I Experimental Set-up}

The apparatus was constructed in the Institute of Iron and Steel Technology of the Technische Universität Bergakademie Freiberg, Germany, and it was described in a previous work. ${ }^{(8)}$ A schematic view is given in Figure I. It consists basically of two systems: an observation system and a thermocouple system. In a vacuum chamber there are two water-cooled inserts left and right. Both of them hold a B-type thermocouple at tips. Each thermocouple is connected to a separate thermocouple controller. The material under study is melted directly on thermocouple in vaccum chamber. The thermocouple remains inside an additional heating, i.e. a kanthal coil which reduces heat losses from the sample to the surroundings.

With this method it is possible to measure the temperature with a thermocouple while it is heated simultaneously. A computer manages the two thermocouple controllers, controlling individually heating and cooling conditions. A software superimposes information about time, temperature and sample image into videos files in a real-time system.

At Figure 2 it can be seen a picture of one typical thermocouple, which is produced welding two platinum wires (Pt30Rh and Pt6Rh) with a special technique. The welding must be nearly perfect to avoid measurement errors. For each material under study one particular thermocouple is used.

\subsection{Experimental Procedure}

\subsection{Preparation of slag samples and investigation procedure}

The composition of the slags which were investigated can be seen at Table I. They were produced from $\mathrm{CaCO}_{3}, \mathrm{SiO}_{2}, \mathrm{TiO}_{2}, \mathrm{Na}_{2} \mathrm{CO}_{3}$ and $\mathrm{Al}_{2} \mathrm{O}_{3}$. They were pre-melted in carbon crucibles using an induction furnace. Then they were milled, decarburized at $700^{\circ} \mathrm{C}$ during 5 hours (except CST) in a muffle furnace and after analysed through X-ray Fluorescence (XRF). The carbon content was determined through LECO CS 244.

To execute the experiments small portions of premelted slags $(5-10 \mathrm{mg}$ ) were pressed and put on the thermocouple tip. With the substances in the vacuum chamber it was applied 5 min of vacuum at 10 mbar. Then, the vessel was filled with Ar, maintaining a flux of $300 \mathrm{l} /$ hour during ten minutes and also during the measurements. The slag samples were heated and melted directly on the tip of the thermocouples, using one particular thermocouple per slag. After melting very high cooling rates (higher than $3000^{\circ} \mathrm{C} / \mathrm{min}$ ) were applied down to the desired temperature; from this point up to the beginning of the crystallisation the incubation time is measured by direct observation. With the incubation times for different temperatures time-temperature-transformation (TTT) diagrams are built.

For the $\mathrm{Na}_{2} \mathrm{O}$-bearing slags the samples were maintained at $1600^{\circ} \mathrm{C}$ during short time (60 seconds) after heating at $1000^{\circ} \mathrm{C} / \mathrm{min}$. At this high temperature the samples are completely melted in a few seconds. It was clearly observed that if the same sample is used to do many determinations at the same temperature the incubation
I - Vaccum chamber

2 - Insert

3 - Thermocouple

4 - Sealed window

5 - Electronic circuit

6 - CCD camera

7 - Computer control

8 - Lamp

9 - Additional heating

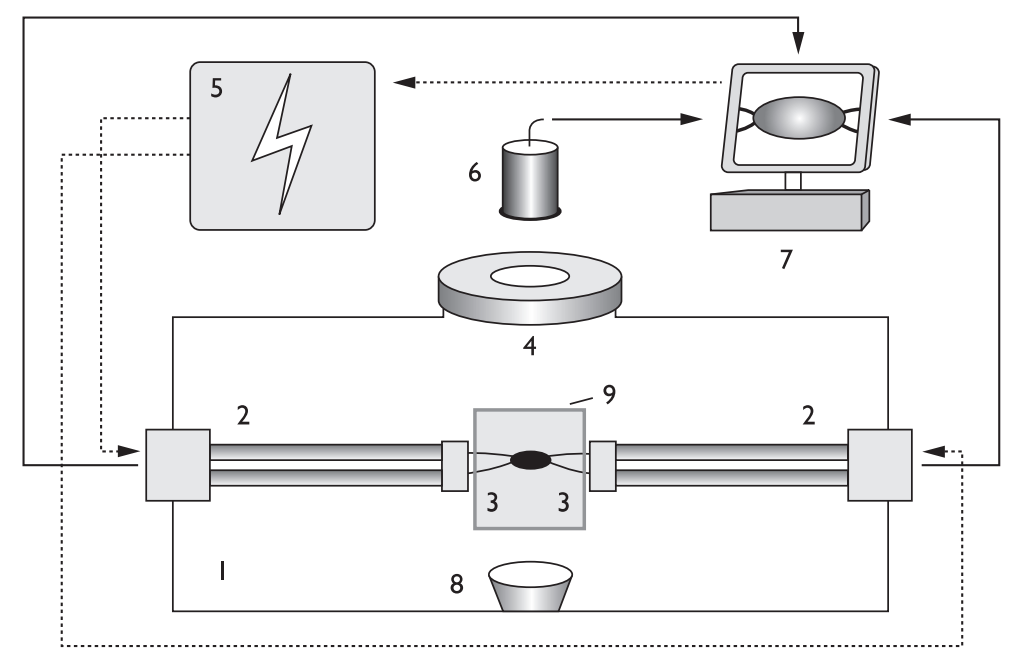

Figure I. Schematic view of the experimental set-up. 


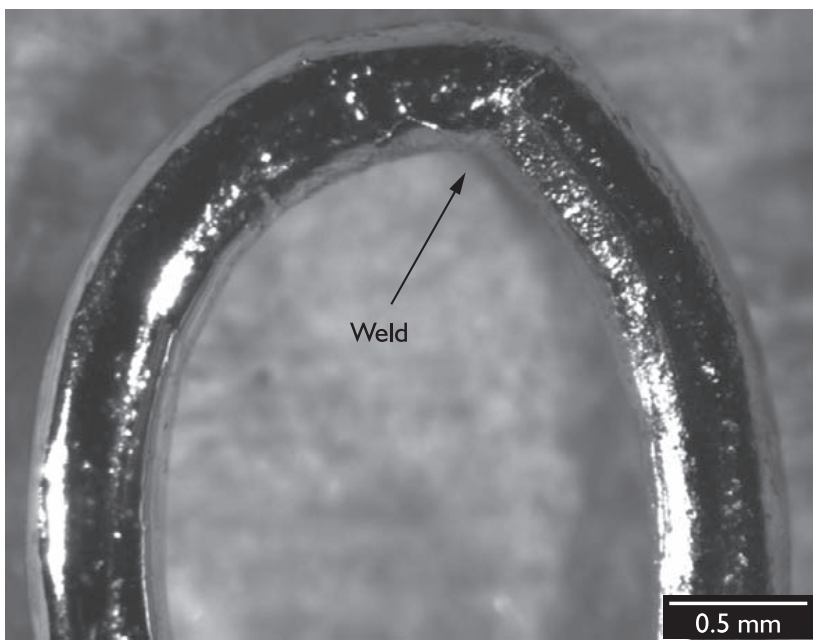

Figure 2. Typical thermocouple used in the experiments (tip), showing the region where slags are melted. Image obtained from a stereomicroscope.

Table I. Composition of the slags (\%wt.) B means the ratio $\% \mathrm{CaO} / \% \mathrm{SiO}_{2}$

\begin{tabular}{cccccccc}
\hline & $\% \mathrm{CaO}$ & $\% \mathrm{SiO}_{2}$ & $\% \mathrm{TiO}_{2}$ & $\% \mathrm{Na}_{2} \mathrm{O}$ & $\%_{2} \mathrm{O}_{3}$ & $\% \mathrm{C}$ & $\mathrm{B}$ \\
\hline CST & 35.6 & 46.3 & 18.1 & & & 0.590 & 0.8 \\
CSTNA_1 & 33.6 & 41.3 & 16.5 & 7.1 & 1.5 & 0.073 & 0.8 \\
CSTNA_2 & 30.1 & 46.8 & 16.4 & 5.4 & 1.3 & 0.034 & 0.6 \\
CSTNA_3 & 31.6 & 48.1 & 15.5 & 3.7 & 1.1 & 0.032 & 0.7 \\
CSTNA_4 & 30.9 & 42.3 & 15.2 & 6.4 & 5.2 & 0.038 & 0.7 \\
\hline
\end{tabular}

time became longer. The reason for this effect is $\mathrm{Na}_{2} \mathrm{O}$ loss at high temperatures, assuming that the higher the $\% \mathrm{Na}_{2} \mathrm{O}$ content the higher the crystallisation tendency. To avoid this problem the maximum amount of measurements per sample was ten. Each point in the TTT diagrams is the average of a minimum of three measurements.

From the video files recorded during the experiments observations related to the morphology of crystals were done at different temperatures.

\subsubsection{Examination of the accuracy of the apparatus}

Firstly the accuracy of the apparatus was checked measuring the crystallisation temperature of $\mathrm{Na}_{2} \mathrm{SO}_{4}$, $\mathrm{CaF}_{2}$ and $\mathrm{K}_{2} \mathrm{SO}_{4}$. The crystallisation temperature $\left(\mathrm{T}_{\text {cryst. }}\right)$ is defined as the point where the first crystals can be detected visually through the recorded video files. The procedure before high temperature experiments (vacuum, Ar flow) is described above. Afterwards, the substances were melted $100^{\circ} \mathrm{C}$ above their literature melting points and cooled at $30^{\circ} \mathrm{C} / \mathrm{min}$. Their melting points (m.p.) from Patnaik ${ }^{(9)}$ are: $\mathrm{Na}_{2} \mathrm{SO}_{4}-884^{\circ} \mathrm{C}, \mathrm{CaF}_{2}-1418^{\circ} \mathrm{C}, \mathrm{K}_{2} \mathrm{SO}_{4}-1069^{\circ} \mathrm{C}$

\section{RESULTS AND DISCUSSION}

\section{I Examination of the Accuracy of the Apparatus}

The differences between the literature melting points ${ }^{(9)}$ and the crystallisation temperatures for $\mathrm{Na}_{2} \mathrm{SO}_{4}$, $\mathrm{CaF}_{2}$ and $\mathrm{K}_{2} \mathrm{SO}_{4}$ which were measured by SHTT are indicated at Figure 3. Twelve experiments were performed for each substance (experiments I-6 were done to the left side and experiments 7-12 to the right side according to Figure I).

Assuming a normal distribution for $\Delta \mathrm{T}_{\text {cryst. }}$ average values and standard deviations can be calculated, see Table 2. The average values are very near of the melting points from literature and the scattering is low. The small observed differences can be related to particular conditions for heterogeneous nucleation. Regarding $\mathrm{Na}_{2} \mathrm{SO}_{4}$ and $\mathrm{CaF}_{2}$ the crystallisation is intense and happens suddenly; in this situation it is easy to define accurately the beginning of the crystallisation. For $\mathrm{K}_{2} \mathrm{SO}_{4}$, the substance which presents higher standard deviation, the crystallisation is not so intense and normally takes some seconds to be finished.

\subsection{TTT Diagrams for Slags in the $\mathrm{CaO}-\mathrm{SiO}_{2}-\mathrm{TiO}_{2}-$ $\mathrm{Na}_{2} \mathrm{O}$ System}

The slag CST has relatively low liquidus temperature $\left(1366^{\circ} \mathrm{C}\right.$, calculated from FactSage 6.0$)$ and relatively low viscosity (ca. IOP at $1400^{\circ} \mathrm{C}$, from Schenck and Frohberg $\left.{ }^{(10)}\right)$. This slag system has been considered as a starting point to the development of fluorine-free mould powders. The slag CST has a composition similar to a slag studied in

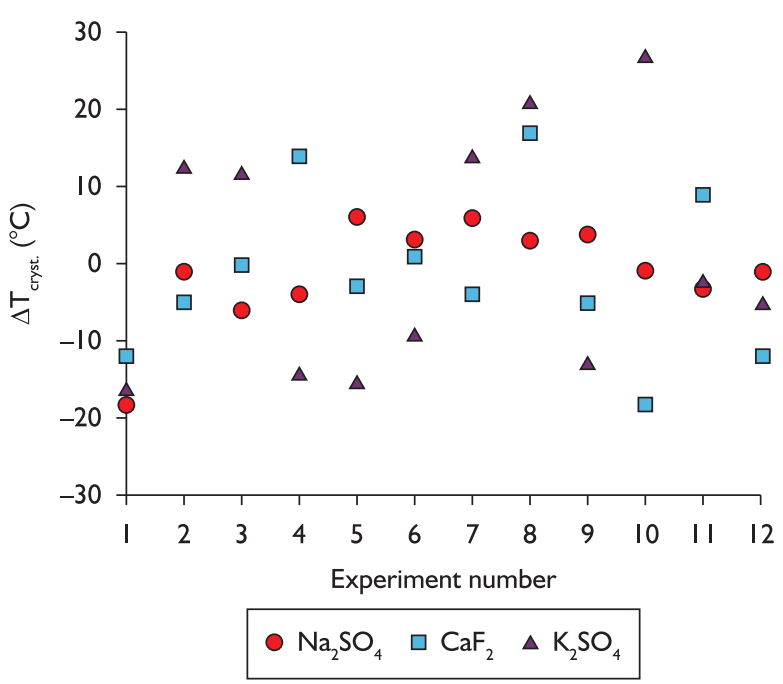

Figure 3. Comparison between literature and results from the present work. $\Delta \mathrm{T}_{\text {cryst. }}$ is the difference between the literature melting point $^{(9)}$ and the crystallisation temperature which was measured by SHTT. 
Table 2. Comparison between literature melting points and crystallisation temperatures measured by $\mathrm{SHTT}\left(\mathrm{T}_{\text {cryst. }}\right)$. For each substance 12 measurements were performed

\begin{tabular}{cccc}
\hline Substance & m.p. literature ${ }^{(9)}$ & $\begin{array}{c}\text { Average } \\
\mathbf{T}_{\text {cryst. }}\end{array}$ & $\begin{array}{c}\text { Standard } \\
\text { deviation } \mathbf{T}_{\text {cryst. }}\end{array}$ \\
\hline $\mathrm{Na}_{2} \mathrm{SO}_{4}$ & $884^{\circ} \mathrm{C}$ & $883^{\circ} \mathrm{C}$ & $6.6^{\circ} \mathrm{C}$ \\
$\mathrm{CaF}_{2}$ & $1418^{\circ} \mathrm{C}$ & $1417^{\circ} \mathrm{C}$ & $10.6^{\circ} \mathrm{C}$ \\
$\mathrm{K}_{2} \mathrm{SO}_{4}$ & $1069^{\circ} \mathrm{C}$ & $1071^{\circ} \mathrm{C}$ & $15.4^{\circ} \mathrm{C}$ \\
\hline
\end{tabular}

another work, ${ }^{(5)}$ whose TTT diagram was built from differential thermal analysis (DTA). Despite of using another technique the reported incubations times are similar to the results of the present work.

The slag CSTNA_I was designed to have basicity and $\mathrm{TiO}_{2}$ content similar to the slag CST, as it can be seen at Table I. The TTT diagrams for the slags CST and CSTNA_I are at Figure 4, in logarithmic scale. The $\mathrm{Na}_{2} \mathrm{O}$-bearing slag CSTNA_I has higher crystallisation rate. $\mathrm{Na}_{2} \mathrm{O}$ addition shortens intensely the incubation times from the $\mathrm{CaO}-\mathrm{SiO}_{2}-\mathrm{TiO}_{2}$ slag system.

For doing a comparison with an industrial slag, at Figure 4 it can also be seen the TTT diagram of a commercial mould powder normally employed in the continuous casting of stainless steels, whose TTT diagram was also built using SHTT. ${ }^{(11)}$. This commercial mould powder contains $\mathrm{CaF}_{2}$ and $\mathrm{Na}_{2} \mathrm{O}$ and does not contain $\mathrm{TiO}_{2}$.

With this new finding i.e. the fact that there is a great increase of the crystallisation rate when adding $\mathrm{Na}_{2} \mathrm{O}$ from the $\mathrm{CaO}-\mathrm{SiO}_{2}-\mathrm{TiO}_{2}$ system, other slags were produced with a lower $\mathrm{Na}_{2} \mathrm{O}$ content to study the possi-

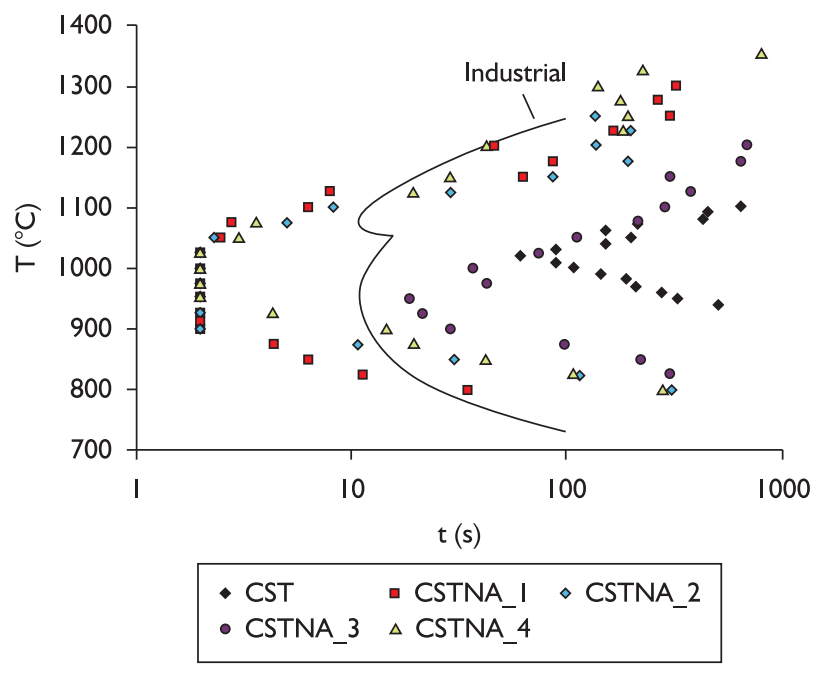

Figure 4. TTT diagrams for slags in the $\mathrm{CaO}-\mathrm{SiO}_{2}-\mathrm{TiO}_{2}-\mathrm{Na}_{2} \mathrm{O}$ system (composition in Table I) and also for a F-bearing industrial slag. (II) bility of controlling the crystallisation. From CSTNA_I were produced CSTNA_2 and CSTNA_3, maintaining basicity and $\mathrm{TiO}_{2}$ content in similar levels. As expected it was observed shorter incubation times, especially to CSTNA_3 which has lower $\mathrm{Na}_{2} \mathrm{O}$ content.

Industrial mould slags contain $\mathrm{Al}_{2} \mathrm{O}_{3}$ and because of this fact it was also produced CSTNA_4, which is a slag with composition similar to CSTNA_I but containing more $\mathrm{Al}_{2} \mathrm{O}_{3}$. Despite of having a higher $\overline{\mathrm{Al}}_{2} \mathrm{O}_{3}$ content the incubation times are similar, except at lower temperatures where there is some difference.

Industrial slags are more complex, since they have more components. Anyway, these results can be used as a reference for future developments when designing fluorine-free mould powders for slab casting, where the control of crystallisation is imperative. In this way $\mathrm{Na}_{2} \mathrm{O}$ -bearing and $\mathrm{TiO}_{2}$-bearing raw materials could be used to mould powders industrial production; these raw materials can be less expensive than other possibilities such as $\mathrm{B}_{2} \mathrm{O}_{3}$ and $\mathrm{Li}_{2} \mathrm{O}$.

\subsection{Crystals Morphology}

It was observed for all the slags that the morphology of the crystals varies with temperature. Two kinds of crystals were observed: columnar grains (which seem to grow unidirectionally from surface to center of the sample) and equiaxed grains (which seem to grow radially in the liquid slag). It was reported in literature that, for crystallisation in mould fluxes, both columnar and equiaxed grains grow dendritically. ${ }^{(12)}$

The crystals have dendritic appearance at higher temperatures and become small and dense at lower temperatures. For these last ones, which are formed in the middle of the liquid slag for higher degree of undercooling, they can be explained by homogeneous nucleation.

Below at Figure 5 there are some images got from the recorded video files for the slag CSTNA_I and some observations related to the morphology of the crystals for this particular slag.

Firstly, at Figure 5a it is showed an image of the slag completely liquid at $1600^{\circ} \mathrm{C}$, with the lamp below the sample off. It is normal to have some bubbles around the thermocouple borders, even using decarburized samples - the reason for the existence of these bubbles is not clear. For all the experiments the lamp below the sample was turned on; in this way the resolution image is higher.

At higher temperatures there are columnar grains and equiaxed grains; it is common to observe dendrites nucleating from thermocouple borders. These temperatures correspond to long incubation times and consequently to lower crystallisation rates.

At lower temperatures (e.g. Figure $5 \mathrm{e}-\mathrm{g}$ ) there are equiaxed grains growing from different points in the sample. 

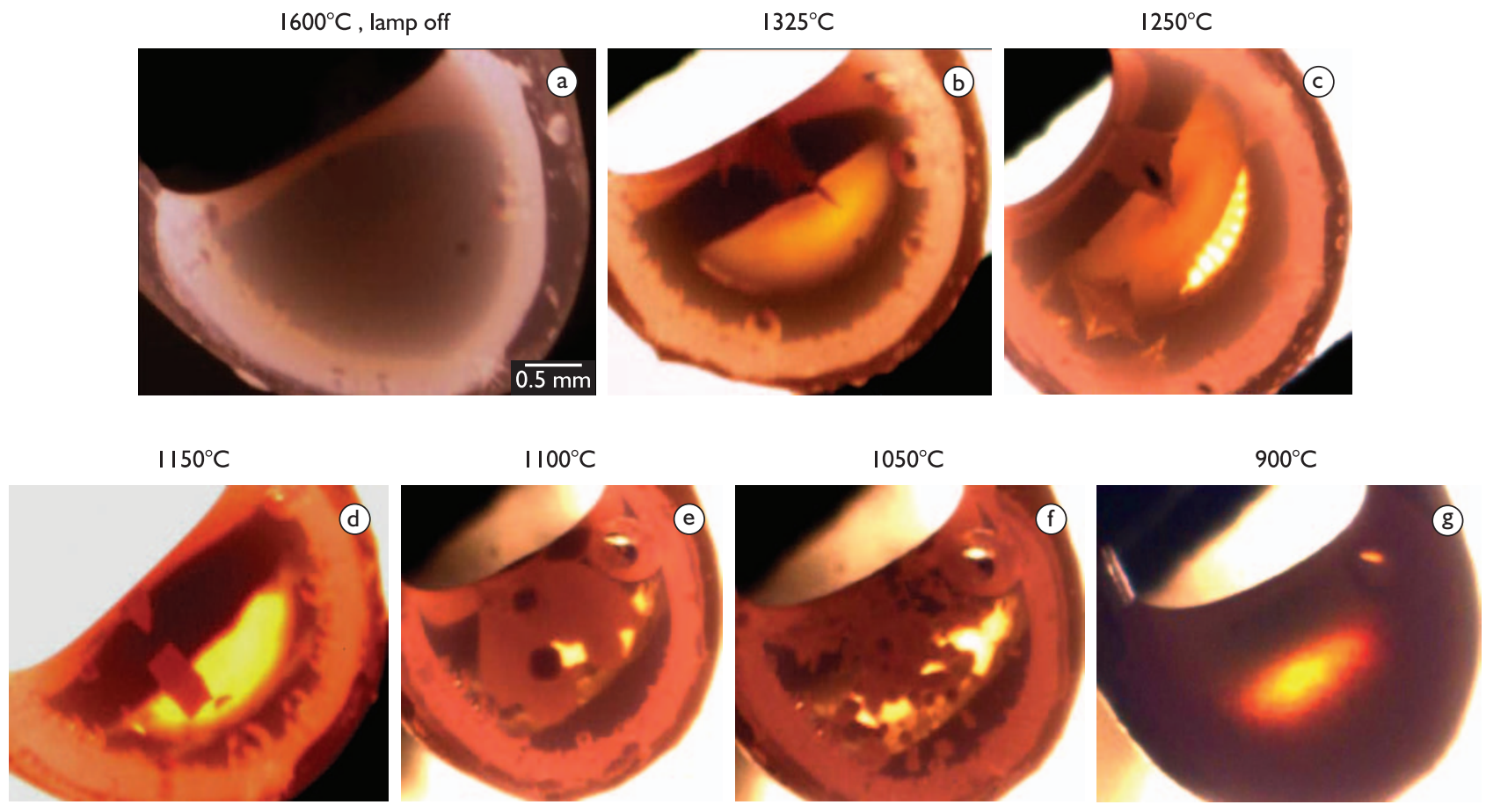

Figure 5. Images got from the recorded video files for the experiments performed with the slag CSTNA_I at different temperatures.

At $900^{\circ} \mathrm{C}$ the samples are translucent, see Figure $5 \mathrm{~g}$. The incubation time is 2 seconds and the samples are completely opaque in only 4 seconds.

In a general way crystals can grow from the liquid slag or from solid glass (devitrification), depending on temperature. With SHTT it is difficult to determine if the sample is liquid slag or solid glass. Anyway, for transparent slags crystallisation can be observed in both situations, though at lower temperatures the conditions for visibility are not ideal.

\section{CONCLUSIONS}

The results indicate that the system $\mathrm{CaO}-\mathrm{SiO}_{2}$ $\mathrm{TiO}_{2}-\mathrm{Na}_{2} \mathrm{O}$ can be used as substitute for F-bearing commercial mould powders, regarding crystallisation behaviour, since the incubation times at TTT diagrams and consequently the crystallisation rates can be similar to commercial products. This is possible because addition of $\mathrm{Na}_{2} \mathrm{O}$ shorten intensely the incubation times from the $\mathrm{CaO}-\mathrm{SiO}_{2}-\mathrm{TiO}_{2}$ slag system. In this way, $\mathrm{Na}_{2} \mathrm{O}$-bearing and $\mathrm{TiO}_{2}$-bearing raw materials could be used to produce mould powders. Besides, the results also indicate that $\mathrm{Al}_{2} \mathrm{O}_{3}$ content up to $5.2 \%$ do not change significantly the incubation times of $\mathrm{CaO}-\mathrm{SiO}_{2}-$ $\mathrm{TiO}_{2}-\mathrm{Na}_{2} \mathrm{O}$ slags, considering the compositions of the present work.

\section{Acknowledgements}

The author Jeferson L. Klug wishes to express his gratitude to the Brazilian Science and Technology National Council (CNPq) for the granted scholarship, and to gratefully acknowledge the financial support from the company Stollberg do Brasil.

\section{REFERENCES}

I MILLS, K. C.; FOX, A. B. The role of mould fluxes in continuous casting - so simple yet so complex. ISIJ International, v. 43, n. 10, p. 1479-86, 2003. http://dx.doi.org/10.2355/isijinternational.43.1479

$2 \mathrm{HOOLI}$, P. Study on the layers in the film originating from the casting powder between steel shell and mould and associated phenomena in continuous casting of stainless steel. 2007. Thesis (Doctoral in Materials Science and Engineering) - Helsinky University of Technology, Helsinky, 2007.

3 ORRLING, C. et al. Observations of the melting and solidification behavior of mold slags. Iron \& Steelmaker, v. 27, n. I, p. 53-63, 2007. 
Klug et al.

4 SCHULZ, T. et al. Entwicklung umweltfreundlicher Stranggießschlacken. Stahl Und Eisen, v. I28, n. 4, p. 65-78, Apr. 2008.

5 NAKADA, H.; NAGADA, K. Crystallization of CaO-SiO2-TiO2 slag as a candidate for fluorine free mold flux. ISIJ Internationa, v. 46, n. 3, p. 44I-9, Mar. 2006. http://dx.doi.org/I0.2355/isijinternational.46.44I

6 WEN, G. et al. Development of fluoride-free mold powders for peritectic steel slab casting. ISIJ International, v. 47, n. 8, p. II I7-25, Aug. 2007. http://dx.doi.org/I0.2355/isijinternational.47. I I I

7 XIN QI; WEN, G.-H.; PING TANG. Investigation on heat transfer performance of fluoride-free and titanium-bearing mold fluxes. Journal of Non-Crystalline Solids, v. 354, n. 52-4, p.5444-52, 2008.

8 LACHMANN, S.; SCHELLER, P. R. Effect of Al2O3 and CaF2 on the solidification of mould slags and the heat transfer through slag films. In: INTERNATIONAL CONFERENCE ON MOLTEN SLAGS, FLUXES AND SALTS, 8., 2009, Santiago. Proceedings... Santiago: Gecamin, 2009. p. II 01.

9 PATNAIK, P. Handbook of inorganic chemicals. New York: McGraw-Hill, 2003.

IO SCHENCK, H.; FROHBERG, M. Viskositätsmessungen an flüssigen Schlacken des Systems CaO-SiO2-TiO2 im Temperaturbereich von 1300 bis $1600^{\circ} \mathrm{C}$. Archiv für das Eisenhüttenwesen, v. 33, n. 7, p. 423-5, July 1962.

I I KASHIWAYA, Y.; CICUTTI, C. E.; CRAMB, A. W. n Investigation of the crystallization of a continuous casting mold slag using the single hot thermocouple technique. ISIJ International, v. 38, n. 4, p. 357-65, Apr. 1998. http://dx.doi. org// 0.2355/isijinternational.38.357

I2 MIZUNO, H. et al. Analysis of the crystallization of mold flux for continuous casting of steel. ISIJ International, v. 48, n.3, p. 277-85, Mar. 2008. http://dx.doi.org/I0.2355/isijinternational.48.277

Recebido em: $26 / 08 / 20 \mathrm{II}$

Aceito em: $21 / 12 / 2011$ 